\title{
The effects of Aerobic exercise intensity participation training on body composition, health related fitness and quality of life in elderly women
}

\author{
Hyoung-jun $\mathrm{Kim}^{1}$ \& Joon-sung Park ${ }^{2 *}$ \\ ${ }^{1}$ Liansoft Inc. \& ${ }^{2}$ Silla University
}

\begin{abstract}
[Purpose] The purpose of this study was to investigate the effects of aerobic exercise intensity on body composition, health related fitness, and quality of life in elderly women. [Methods] 48 elderly women over 65 years of age without physical and mental problems were assigned to four groups: control group, low intensity, moderate intensity, and high intensity aerobic training group. The aerobic exercise group applied a heart rate reserve (HRR) to low-intensity group (HRR 40-55\%), moderate intensity group (HRR 55-70\%), high intensity group (HRR> 70\%) for 12 weeks, 3 times a week for 20 minutes a day. Subjects of the control group were to maintain their usual lifestyles during the same intervention period. Body composition, health related fitness, and quality of life were measured and analyzed using repeated two-way ANOVA. [Results] The main results obtained in this study are as follows. 1) There was a significant decrease in sitting forward bending in the low intensity group and a significant increase in EQ-VAS. 2) There was a significant decrease in body weight, BMI, and 6 minutes walking in the moderate intensity group, and a significant increase in grip strength and EQ-VAS. 3) The high intensity group showed a significant decrease in weight, BMI, waist circumference, sitting forward bending, and 6 minutes walking, and a significant increase in grip strength, sit and stand, functional reach, and $\mathrm{VO}_{2} \max$. On the other hand, there was no significant change in all variables in the control group. [Conclusions] In conclusion, aerobic training was found to be effective for body composition, health related fitness and quality of life in elderly women. In particular, it can be concluded that high intensity aerobic training is effective for health related fitness, and low and moderate intensity aerobic exercise is effective for improving quality of life.
\end{abstract}

Key Words: elderly women, aerobic exercise, body composition, health related fitness, quality of life.

\section{서 론}

노화와 노인인구의 증가는 개인의 신체적, 정신적으로 악영향은 물론 사망률, 의료비, 그리고 요양비 등의 증가

논문 투고일 : 2019. 11. 18.

논문 수정일 : 2019. 12. 20.

게재 확정일 : 2020. 01. 07.

* 교신저자 : 박준성(joon3750@ silla.ac.kr).

* 이 논문은 2015년 정부재원(교육부)으로 한국연구재단의 지원 을 받아 수행된 연구임(NRF-2015S1A5B5A07043222).
와 같은 심각한 사회문제를 나타내기 때문에 이를 해결하 기 위한 방법이 필요한 실정이다(Statistic Korea, 2018). 또한 노인에 대한 문제들이 나타나면서 다양한 해결 방법들이 제시되었는데 그중 운동 트레이닝을 통해 생활습관을 개선하는 것은 노인의 체력을 증가시키고 체 중감소와 대사기능의 향상으로 만성질환을 개선하는데 효 과적인 것으로 여러 연구에서 검증되었다(Santos et al., 2012; Hall \& Marteau, 2014; Bauman et al., 2016). 이와 관련하여 세계보건기구(world health organization: 
$\mathrm{WHO}$ )에서는 노인을 위한 건강지침으로 일주일에 150 분 이상의 중강도 유산소 운동 또는 75 분 이상의 고강도 유산소 운동을 권장하였고(WHO, 2010), 미국스포츠의 학회(american college of sports medicine: ACSM)에 서는 노인을 위한 건강 치침으로 일주일에 150-300분 정 도의 중강도 유산소 운동 또는 75-100분 정도의 고강도 유산소 운동과 주 2회 저항성 운동을 권장하였다 (ACSM, 2013). 이와 더불어 국내의 경우에도 다양한 연 구를 통해 규칙적인 운동이 노인의 건강과 관련된 다양한 문제점들을 개선하기 위한 방법으로 권장되고 있지만 (Park \& Yang, 2012; Jung \& Sung, 2013; Park et al., 2014), 국내 노인의 신체활동 참여는 저조한 실정이 며(Ministry of Culture, Sports and Tourism, 2012), 2008년에 노인을 위한 노인장기요양보호법이 시행되었 음에도 불구하고 노인들에 대한 체계적인 건강관련 정책 과 프로그램 개발은 미흡한 실정이다(Sun et al., 2008).

노인에 대한 건강관련 프로그램에서는 노인의 운동 트 레이닝 참여가 체력향상에 긍정적인 영향을 미치는 것으 로 보고되었다(Chou et al., 2012; Kang et al., 2014). 그러나 대부분의 연구는 일정강도의 운동 트레이닝에 대 한 효과만을 보고하였으며, 동일한 운동을 적용하여 운동 강도별 차이를 비교한 연구는 전무한 실정이다.

인체는 생리학적으로 고강도 트레이닝 시 체력향상에 효과적인 것을 알 수 있으나(Gibala et al., 2012; Landaeta-Diaz et al., 2013), 노인의 경우 성인과 달리 신체적, 정신적으로 허약하기 때문에 건강과 체력을 유지 시킬 수 있는 적절한 강도의 운동을 적용하는 것이 필요 하며, 이러한 적용은 자발적인 참여와 장기간 참여를 도 모할 수 있을 것으로 보고하였다(Phillips et al., 2004). 따라서 단순히 노인의 체력을 향상시키기 보다는 트레이 닝에 자발적으로 참여하여 장기간 규칙적인 신체활동에 참여할 수 있는 적절한 강도의 운동 트레이닝의 제시가 필요하다.

노인의 자발적인 장기간 운동참여는 일상생활 체력의 증가를 통하여 독립적인 생활을 영위하는데 긍정적인 영 향을 주며, 이와 같은 결과는 노인의 삶의 질을 증가시키 는 것으로 보고되었다(Marengoni et al., 2011).

삶의 질은 건강에 직접적인 영향을 미치는 요인으로 건강의 정의와 연관되어 발전된 추상적인 개념이며(Yim
$\&$ No, 2010), 노인의 경우 성공적인 노화를 위하여 건강 한 삶과 행복 등을 추구하기 때문에 삶의 질을 증가시키 는 것이 중요한 요인으로 보고되었다(Kim \& Ahn, 2014). 국내에서도 삶의 질의 중요성을 인식하여 2005 년부터 국내에서는 건강관련 삶의 질을 평가하고 있다 (Ministry of Health and Welfare, 2006).삶의 질의 중 요성이 대두되면서 삶의 질을 향상시키기 위한 연구들이 국내외적으로 활발하게 진행되고 있다(Kim et al., 2012; Oh, 2014; Delforge et al., 2012; Laudisio et al., 2013). 그 중 운동 트레이닝은 삶의 질뿐만 아니라 체력, 대사기능, 그리고 사회성 등을 향상시키고(Yoon \& Kim, 2011; Lee et al., 2011), 체중, 만성질환, 낙 상, 우울, 그리고 불안 등을 감소시키데 효과적인 것으로 보고되었다(Zhao et al., 2012). 특히 노인의 경우 젊은 성인과 달리 체력의 향상을 위한 신체활동보다는 보다는 즐겁고 행복한 신체활동을 선호하는 것으로 나타났다 (Kim et al., 2005).

국내에서도 운동 트레이닝과 삶의 질에 대한 연구들이 일부 수행되었으나(So et al., 2010; Park \& Kim, 2014), 단순히 운동 프로그램 참여 후 삶의 질의 변화에 대한 연구이며, 아직까지 운동강도에 따른 삶의 질의 변 화에 대한 연구는 국내외적으로 미흡한 실정이다.

성공적인 노화를 위하여 건강이 주요 요인이며, 그중 신체활동은 그 효과성이 높은 방법이다(Pietrzak et al., 2014). 그러나 신체활동의 참여에 대한 중요성 및 효과 에 대한 인식은 높아졌음에도 불구하고 참여율은 저조한 실정이다(Ministry of Culture, Sports and Tourism, 2012). 이를 개선하기 위하여 국민의 건강증진을 위한 국가사업의 일환으로 진행된 '국민체력 100 노인기 효과 검증'에서 노인을 대상으로 트레이닝을 실시한 결과, 건 강관련체력 및 사회심리적 특성에서 긍정적인 효과가 있 는 것으로 나타났다(Park et al., 2014).

건강관련체력은 운동강도가 높을수록 증가되었으나, 건강과 관련된 사회심리적 변인인 자존감, 행복감, 자기 효능감, 그리고 결과 기대감에서는 운동강도가 낮을수록 높게 나타났다(Park et al., 2014). 반면, Bize et al.(2007)의 연구에서는 건강관련 삶의 질의 변화는 신 체활동과 긍정적인 관계가 있으며, 운동강도가 증가 될수 록 높다고 보고하였다. 이와 같은 선행연구의 결과를 종 
합해 볼 때, 노인의 경우 고강도의 운동보다는 즐기면서 하는 여가운동의 형태가 사회심리적인 요소를 증가시키 는데 효과적일 것으로 판단되며, 이러한 효과를 규명할 수 있는 적절한 운동강도의 설정이 필요할 것으로 판단된다.

\section{연구 방법}

\section{연구 대상자}

본 연구의 대상자는 B시에 거주하고 있는 65 세 이상 노인 여성을 대상으로 선정하였으며, 연구대상자의 선정 기준은 인지적으로 의사소통의 문제가 없고, 의학적 또는 정신병적 질환으로 인한 심각한 기능 손상이 없으며, 신 체적 · 심리적으로 건강한 자로 하였다. 연구대상자 제외 기준은 1) 근골격계 질환으로 규칙적인 운동 트레이닝에 참여하지 못하는 자, 2) 연구시작 3개월 이내에 주 2회 (최소 1회 20분) 이상 규칙적인 운동 트레이닝에 참여한 자, 3) 2회 측정 시 $160 / 100 \mathrm{mmHg}$ 이상인 자, 4) 의사 소통에 문제가 있는 자, 5) 불안정한 협심증(흥통), 통제 할 수 없는 고혈압, 심장마비, 관절염, 만성신부전증, 간 질, 그리고 경련 등의 병력과 정신병적 질환으로 인한 심 각한 기능 손상이 있는 자로 하였다.

본 연구에서 적용한 유산소 운동강도별 기준은 $\operatorname{ACSM}(2010)$ 을 참고하였으며, 선정된 대상자를 네 집단 으로 구성하여 여유심박수(heart rate reserve: HRR)를 적용한 1) 저강도 유산소 운동집단 (low intensity aerobic exercise group: LA집단)은 HRR 40-55\%, 2) 중강도 유산소 운동집단(moderate intensity aerobic exercise group: MA집단)은 $\mathrm{HRR} 55 \sim 70 \%$, 3) 고강도 유산소 운동집단(high intensity aerobic exercise group: HA집단)은 $\mathrm{HRR} 70 \%$ 이상으로 유산소 운동 실 시하는 세 집단과, 4) 통제집단(control group: CON집 단)을 포함한 네 집단을 무선할당하여 12 주간 참여시켰 다. 총 57명이 모집되었으나, 실험 중 개인적인 이유로 인하여 CON집단에서 2명, LA집단에서 3명, MA집단에 서 2명, 그리고 $\mathrm{HA}$ 집단에서 2명이 탈락하여 최종적으로 48 명의 데이터를 분석하였다. 사전검사 실시에 앞서 오 리엔테이션을 통하여 연구 내용을 설명하고 연구에 자발 적으로 참여하고자 하는 대상으로부터 검사 동의서를 받 은 후 연구에 참여하도록 하였다. 연구 시작 전 모든 연구 의 계획에 대하여 S대학교 생명윤리위원회의 승인을 받 았으며 (1041449-201606-HR-004), 대상자의 신체적 특성은 〈Table 1〉에 제시된 바와 같다.

\section{측정 항목과 방법}

\section{1) 체격과 신체구성}

체격 변인으로 신장은 수동식 일반 신장계 (Samhwa, 한국)를 이용하여, 그리고 체중(body weight)은 전자식 체중계(CAS-150 kg, DW-150, Korea)를 이용하여 측 정하였다. 체질량지수(body mass index: $\mathrm{BMI}$ )는 $\mathrm{kg}$ 단 위 체중을 $\mathrm{m}$ 단위 신장의 제곱 값으로 나누어 산출하였 다. 혈압 측정법은 비의존성 상완의 전주부 $2 \mathrm{~cm}$ 상방에

Table 1. Physical characteristics of subjects

$($ mean $\pm \mathrm{SE})$

\begin{tabular}{|c|c|c|c|c|c|}
\hline \multirow{2}{*}{ Variables } & \multicolumn{4}{|c|}{ Groups } & \multirow{2}{*}{$p$} \\
\hline & $\mathrm{CON}(\mathrm{n}=12)$ & $\mathrm{LA}(\mathrm{n}=12)$ & $\operatorname{MA}(\mathrm{n}=12)$ & $\mathrm{HA}(\mathrm{n}=12)$ & \\
\hline Age (yrs) & $71.8 \pm 1.2$ & $70.6 \pm 1.3$ & $70.8 \pm 1.2$ & $70.4 \pm 0.8$ & 0.848 \\
\hline Height (cm) & $153.6 \pm 1.2$ & $154.8 \pm 1.6$ & $153.4 \pm 1.7$ & $154.5 \pm 0.9$ & 0.875 \\
\hline Body weight (kg) & $56.5 \pm 1.9$ & $59.4 \pm 2.6$ & $57.0 \pm 2.4$ & $52.7 \pm 1.4$ & 0.181 \\
\hline Body mass index $\left(\mathrm{kg} \cdot \mathrm{m}^{-2}\right)$ & $23.9 \pm 0.6$ & $24.7 \pm 0.8$ & $24.2 \pm 0.8$ & $22.1 \pm 0.8$ & 0.089 \\
\hline Systolic blood pressure $(\mathrm{mmHg})$ & $128.3 \pm 4.2$ & $132.0 \pm 5.1$ & $136.3 \pm 3.1$ & $136.8 \pm 4.4$ & 0.454 \\
\hline Diastolic blood pressure (mmHg) & $77.5 \pm 2.6$ & $87.0 \pm 2.6$ & $81.5 \pm 2.7$ & $82.3 \pm 3.1$ & 0.128 \\
\hline Waist circumference $(\mathrm{cm})$ & $87.0 \pm 1.7$ & $89.4 \pm 2.2$ & $86.6 \pm 1.5$ & $82.8 \pm 1.7$ & 0.086 \\
\hline
\end{tabular}

CON: control group, LA: low intensity aerobic exercise group, MA: moderate intensity aerobic exercise group, HA: high intensity aerobic exercise group 
cuff를 감고 oscillometric methods를 이용하였다. 측정 전 30분간의 휴식 시간을 갖고 안정 시 심박수에 도달한 후 안정된 상태에서 수축기(systolic blood pressure)와 이완기 혈압(diastolic blood pressure)을 측정하였다. 허리둘레 (waist circumference)는 배꼽 높이에서, 그리 고 엉덩이둘레는 엉덩이 중 가장 튀어나온 부위의 높이에 서 줄자(Hoechstmass, Germany)로 측정하였다.

\section{2) 건강관련체력}

건강관련체력은 악력 (grip strength), 의자에 앉았다 일어서기 (sit to stand), 앉아 윗몸 앞으로 굽히기 (sit and reach), $3 \mathrm{~m}$ 표적 돌아오기(timed up and go), 눈뜨 고 외발서기(one leg stand to open eye), 동적평형성 (functional reach), 6분 걷기(6 min walk)를 실시하였 다(Rikli \& Jones, 2013).

악력은 악력계(GRIP-D 5101; TAKEI, Co., Japan) 를 손가락 두 번째 마디에 손잡이가 위치하도록 한 후 최 대한 강하게 악력계를 쥐도록 하여 측정하였다. 왼손과 오른손을 각각 2 회씩 측정하여 높은 값을 기록하였다. 의 자에 앉았다 일어서기는 30초 동안 의자에 앉았다 일어 선 횟수를 측정하였다. 앉아서 윗몸 앞으로 굽히기는 발 바닥을 체전굴계에 밀착시킨 상태에서 양손을 최대한 앞 으로 뻗게 한 후 거리를 측정하였다. $3 \mathrm{~m}$ 표적 돌아오기는 의자에 앉은 상태에서 신호와 함께 의자에서 $3 \mathrm{~m}$ 지점에 있는 콘을 최대한 빠른 걸음으로 돌아와 다시 의자에 앉 는데 까지 걸린 시간을 측정하였다. 눈뜨고 외발서기는 양 쪽 다리에서 각 2회씩 실시하여 더 높은 수치를 기록 하였다. 동적평형성은 측정판과 나란히 선 상태에서 양팔 을 몸과 $90^{\circ}$ 가 되도록 앞으로 올린 후 양손을 모아 최대 한 손끝을 멀리 보내도록 하여 손끝이 이동한 거리를 측 정하였다. 6 분 걷기는 직사각형의 트랙을 6 분 동안 걸었 을 때의 이동 거리를 1 회 측정하였다.

\section{3) 삶의 질}

포괄적 삶의 질 지표 (euroQol-5 dimension: $\mathrm{EQ}-5 \mathrm{D}$ ) 는 유럽에서 조직된 EuroQol이 삶의 질을 평가하기 위하 여 개발한 지표이다(euroQol group, 1990; Ock et al., 2013). 운동능력, 자기관리, 일상활동, 통증과 불편감, 그리고 불안과 우울의 5 개 영역으로 구성된 $\mathrm{EQ}-5 \mathrm{D}$ 검사
지를 제시하고, 각 영역별로 3 개 수준으로 답을 하도록 한 후 각 점수를 합산하여 총점을 산출하였다. 총점이 높 을수록 삶의 질이 높은 것을 의미한다.

삶의 질 점수(euroQol-visual analogue scale: $\mathrm{EQ}-$ $\mathrm{VAS})$ 는 최상의 건강상태인 100점과 최저의 건강상태인 0점을 양 끝으로 하는 $\mathrm{VAS}$ (visual analogue scale)에 주관적인 건강상태를 표시하도록 하여 점수를 측정하였다.

\section{처치 방법}

세 집단의 모든 대상자는 12 주간 각각의 유산소 운동 강도에 따른 트레드밀 운동에 참여하였으며, 운동강도는 개인의 최대심박수를 고려하여 실시하였다. 운동프로그 램 중에는 2 인 1 조가 되어서 트레드밀 속도 및 강도를 모 니터링하고 다른 한명은 대상자 운동자각 여부를 매 분마 다 체크함과 동시에 트레드밀 뒤에서 혹시 모를 낙상에 대한 예방을 준비하였다. 개인 및 집단별 운동강도를 설 정하기 위하여 트레드밀(Series 2000, Marquette Electronics, USA)을 이용한 최대운동부하검사를 실시 하였으며, 대상자들의 신체적 능력을 감안하여 '고위험군 을 위한 Bruce protocol'을 적용하였다(Bruce et al., 1973). 검사 시작 후 탈진 시까지 소요된 시간을 측정한 뒤, 이를 McConnell \& Clark(1987)가 제안한 다음의 공식에 대입하여 최대산소섭취량(maximal oxygen uptake: $\left.\mathrm{VO}_{2} \max \right)$ 을 $\mathrm{ml} \cdot \mathrm{kg}^{-1} \cdot \mathrm{min}^{-1}$ 단위로 산출하였다.

- $\mathrm{VO}_{2} \max =2.282 \times$ 시간 +8.545

- 운동프로그램은 ACSM에서 제시한 노인 유산소 운동프로그램으로써, 저강도(HRR 40-50\%), 중 강도( $\mathrm{HRR} \quad 55-70 \%)$, 그리고 고강도( $\mathrm{HRR}$ $>70 \%)$ 유산소 운동을 실시하였다. 본 연구에서 실시한 강도별 유산소 운동프로그램은 〈Table. 2 게 제시된 바와 같다.

※ 참여자의 평균연령을 65 세로 가정한 경우, 저강 도는 98 112 bpm, 중강도는 112 127 bpm, 그리고 고강도는 $127 \mathrm{bpm}$ 이상으로 20 분간 지 속적인 운동수행이 가능하다고 사료되며, 연구 개시전 pilot-test를 실시하여 수행가능 여부를 판단 후 실시하였음. 


\section{자료처리 방법}

본 연구에서 얻은 모든 자료는 $\mathrm{SPSS} \mathrm{PC}^{+}$for Windows (version 22.0) 통계 프로그램을 이용하여 분석하였다. 두 집단에서 얻은 각 종속변인의 기술 통계량을 평균 (mean)과 표준오차(standard error: SE)로 제시하였다. 두 집단 간, 그리고 두 검사 간 종속변인의 평균 차이를
검증하기 위하여 반복 이원변량분석 (repeated two-way ANOVA)을 실시하였다. 집단의 주효과, 검사의 주효과, 또는 집단과 검사의 상호작용이 유의한 경우, 집단 내 두 검사 간 차이는 종속 t-검증(paired t-test)으로, 그리고 검사 내 두 집단 간 차이는 독립 t-검증(independent t-test)으로 분석하였다. 모든 통계 분석의 유의수준(a) 은.05로 설정하였다.

Table 2. Aerobic exercise training program

\begin{tabular}{ccccc}
\hline \hline Item & Type & Intensity & Time & Frequency \\
\hline Warm up & Stretching & RPE 13-15 & 15 min & \\
\cline { 2 - 4 } Main exercise & LA & HRR 40-55\% & 20 min & 3 times / week \\
\cline { 2 - 4 } & MA & HRR 55-70\% & 20 min \\
\cline { 2 - 4 } Cool down & HA & HRR $>70 \%$ & 20 min & 15 min \\
\hline \hline
\end{tabular}

LA: low intensity aerobic exercise group, MA: moderate intensity aerobic exercise group, HA: high intensity aerobic exercise group HRR: heart rate reserve, RPE: rated perceived exertion

Table 3. Change in body composition

$(\operatorname{mean} \pm \mathrm{SE})$

\begin{tabular}{|c|c|c|c|c|c|c|c|c|}
\hline Variables & Groups & Pre & Post & & $\Delta \%$ & & 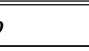 & \\
\hline \multirow{4}{*}{$\begin{array}{l}\text { Body weight } \\
\text { (kg) }\end{array}$} & $\mathrm{CON}$ & $56.5 \pm 1.9$ & $56.4 \pm 1.7$ & & -0.18 & Group & .083 & \\
\hline & LA & $59.4 \pm 2.6$ & $59.2 \pm 2.6$ & & -0.34 & Test & $<.001$ & $\mathrm{H}+$ \\
\hline & MA & $57.0 \pm 2.4$ & $56.7 \pm 2.3$ & $*$ & -0.53 & \multirow{2}{*}{ Group*Test } & \multirow{2}{*}{$<.001$} & \multirow{2}{*}{ H+ } \\
\hline & HA & $52.7 \pm 1.4$ & $51.6 \pm 1.5$ & $* * *$ & -2.09 & & & \\
\hline \multirow{4}{*}{$\begin{array}{l}\text { Body mass index } \\
\quad\left(\mathrm{kg} \cdot \mathrm{m}^{-2}\right)\end{array}$} & $\mathrm{CON}$ & $23.9 \pm 0.6$ & $23.9 \pm 0.6$ & & 0.00 & Group & .707 & \\
\hline & LA & $24.7 \pm 0.8$ & $24.6 \pm 0.8$ & & -0.40 & Test & $<.001$ & H+ \\
\hline & MA & $24.2 \pm 0.8$ & $24.1 \pm 0.8$ & $*$ & -0.41 & \multirow{2}{*}{ Group*Test } & \multirow{2}{*}{$<.001$} & \multirow{2}{*}{ H+ } \\
\hline & HA & $22.1 \pm 0.8$ & $21.7 \pm 0.8$ & $* * *$ & -1.81 & & & \\
\hline \multirow{4}{*}{$\begin{array}{l}\text { Systolic } \\
\text { blood pressure } \\
(\mathrm{mmHg})\end{array}$} & $\mathrm{CON}$ & $128.3 \pm 4.2$ & $127.9 \pm 4.0$ & & -0.31 & Group & .689 & \\
\hline & LA & $132.0 \pm 5.1$ & $132.6 \pm 5.7$ & & 0.45 & Test & .105 & \\
\hline & MA & $136.3 \pm 3.1$ & $132.1 \pm 4.2$ & & -3.08 & \multirow[b]{2}{*}{ Group*Test } & \multirow[b]{2}{*}{.570} & \\
\hline & HA & $136.8 \pm 4.4$ & $129.9 \pm 3.7$ & & -5.04 & & & \\
\hline \multirow{4}{*}{$\begin{array}{l}\text { Diastolic } \\
\text { blood pressure } \\
(\mathrm{mmHg})\end{array}$} & $\mathrm{CON}$ & $77.5 \pm 2.6$ & $76.9 \pm 2.4$ & & -0.77 & Group & .046 & + \\
\hline & LA & $87.0 \pm 2.6$ & $85.4 \pm 2.7$ & & -1.84 & Test & .230 & \\
\hline & MA & $81.5 \pm 2.7$ & $81.4 \pm 2.2$ & & -0.12 & \multirow{2}{*}{ Group*Test } & \multirow{2}{*}{.729} & \\
\hline & HA & $82.3 \pm 3.1$ & $81.3 \pm 2.0$ & & -1.22 & & & \\
\hline \multirow{4}{*}{$\begin{array}{l}\text { Waist } \\
\text { circumference } \\
(\mathrm{cm})\end{array}$} & $\mathrm{CON}$ & $87.0 \pm 1.7$ & $86.2 \pm 1.1$ & & -0.92 & Group & .020 & + \\
\hline & LA & $89.4 \pm 2.2$ & $87.9 \pm 2.0$ & & -1.68 & Test & .014 & + \\
\hline & MA & $86.6 \pm 1.5$ & $85.5 \pm 1.2$ & & -1.27 & \multirow{2}{*}{ Group*Test } & \multirow{2}{*}{.772} & \\
\hline & HA & $82.8 \pm 1.7$ & $80.3 \pm 1.7$ & $* *$ & -3.02 & & & \\
\hline
\end{tabular}

\# CON: control group, LA: low intensity aerobic exercise group, MA: moderate intensity aerobic exercise group, HA: high intensity aerobic exercise group $* p<.05 ; * * p<.01 ; * * * p<.001 \quad+$ Significant main effect and/or interaction. 


\section{연구 결과}

신체구성의 변화는 체중과 BMI에서 집단과 검사의 상 호작용이 유의하게 나타났고, 허리둘레에서 집단과 검사 의 주효과가 유의하게 나타났으며, 이완기혈압에서 집단 의 주효과가 유의하게 나타났다. LA집단과 $\mathrm{CON}$ 집단은 신체구성의 모든 변인에서 유의한 변화가 나타나지 않았
다. 반면 MA집단은 체중 $(p<.05)$ 과 $\mathrm{BMI}(p<.05)$ 에서 유 의한 변화가 나타났고, $\mathrm{HA}$ 집단은 체중 $(p<.001)$, $\operatorname{BMI}(p<.001)$, 그리고 허리둘레 ( $p<.01)$ 에서 유의한 변 화가 나타났다(Table. 3).

체력의 변화는 의자에 앉았다 일어서기, 앉아 윗몸 앞 으로 굽히기, 6 분 걷기, 그리고 동적평형성에서 집단과 검사의 상호작용이 유의하게 나타났고, $3 \mathrm{~m}$ 표적 돌아오

Table 4. Change in Physical fitness

$($ mean \pm SE $)$

\begin{tabular}{|c|c|c|c|c|c|c|c|c|}
\hline Variables & Groups & Pre & Post & & $\Delta \%$ & & $p$ & \\
\hline \multirow{4}{*}{$\begin{array}{c}\text { Grip strength } \\
(\mathrm{kg})\end{array}$} & $\mathrm{CON}$ & $17.38 \pm 1.75$ & $18.08 \pm 1.63$ & & 4.03 & Group & .255 & \multirow{4}{*}{$+H$} \\
\hline & LA & $17.44 \pm 1.62$ & $18.10 \pm 1.26$ & & 3.78 & \multirow{3}{*}{$\begin{array}{c}\text { Test } \\
\text { Group*Test }\end{array}$} & \multirow{3}{*}{$\begin{array}{l}.004 \\
.928 \\
\end{array}$} & \\
\hline & MA & $19.14 \pm 1.31$ & $20.19 \pm 1.12$ & $*$ & 5.49 & & & \\
\hline & HA & $20.34 \pm 0.82$ & $21.41 \pm 0.73$ & $* *$ & 5.26 & & & \\
\hline \multirow{4}{*}{$\begin{array}{l}\text { Sit to stand } \\
\text { (number) }\end{array}$} & $\mathrm{CON}$ & $17.58 \pm 0.60$ & $18.58 \pm 0.56$ & & 5.69 & Group & .039 & + \\
\hline & LA & $19.25 \pm 1.50$ & $21.08 \pm 1.26$ & & 9.51 & \multirow{2}{*}{ Test } & \multirow{2}{*}{$<.001$} & \multirow{2}{*}{ H+ } \\
\hline & MA & $19.58 \pm 1.09$ & $21.83 \pm 1.20$ & & 11.49 & & & \\
\hline & HA & $20.00 \pm 0.90$ & $24.58 \pm 1.29$ & $* *$ & 22.90 & Group*Test & .049 & + \\
\hline \multirow{4}{*}{$\begin{array}{l}\text { Sit and reach } \\
(\mathrm{cm})\end{array}$} & $\mathrm{CON}$ & $18.46 \pm 1.08$ & $18.26 \pm 1.34 \mathrm{a}$ & & -1.08 & Group & .056 & \multirow{4}{*}{$\begin{array}{l}+H \\
+\end{array}$} \\
\hline & LA & $22.96 \pm 1.57$ & $23.67 \pm 1.57 \mathrm{bc}$ & $* *$ & 3.09 & \multirow{3}{*}{$\begin{array}{c}\text { Test } \\
\text { Group*Test } \\
\end{array}$} & \multirow{3}{*}{$\begin{array}{l}<.001 \\
.003 \\
\end{array}$} & \\
\hline & MA & $22.75 \pm 1.77$ & $23.40 \pm 1.58 b \mathrm{bc}$ & & 2.86 & & & \\
\hline & HA & $19.07 \pm 1.31$ & $21.23 \pm 1.29 \mathrm{ac}$ & $* * *$ & 11.33 & & & \\
\hline \multirow{4}{*}{$\begin{array}{l}\text { Timed up } \\
\text { and go } \\
\text { (sec) }\end{array}$} & $\mathrm{CON}$ & $7.39 \pm 0.15$ & $7.39 \pm 0.16$ & & 0.00 & \multirow{4}{*}{$\begin{array}{c}\text { Group } \\
\text { Test } \\
\text { Group*Test }\end{array}$} & .031 & + \\
\hline & LA & $6.85 \pm 0.23$ & $6.61 \pm 0.21$ & & -3.50 & & \multirow{3}{*}{$\begin{array}{l}.046 \\
.668\end{array}$} & \multirow{3}{*}{+} \\
\hline & MA & $7.25 \pm 0.29$ & $6.99 \pm 0.30$ & & -3.59 & & & \\
\hline & HA & $6.77 \pm 0.20$ & $6.48 \pm 0.14$ & & -4.28 & & & \\
\hline \multirow{4}{*}{$\begin{array}{l}6 \text { min walk } \\
(\mathrm{m})\end{array}$} & $\mathrm{CON}$ & $466.75 \pm 27.44$ & $474.63 \pm 22.98$ & & 1.69 & \multirow{3}{*}{$\begin{array}{c}\text { Group } \\
\text { Test }\end{array}$} & \multirow{3}{*}{$\begin{array}{r}.689 \\
<.001\end{array}$} & \multirow{3}{*}{ +H } \\
\hline & LA & $495.28 \pm 18.48$ & $501.25 \pm 15.07$ & & 1.21 & & & \\
\hline & MA & $478.00 \pm 20.23$ & $508.07 \pm 20.55$ & $*$ & 6.29 & & & \\
\hline & $\mathrm{HA}$ & $470.60 \pm 27.34$ & $538.04 \pm 17.33$ & $* *$ & 14.33 & Group*Test & .001 & ++ \\
\hline \multirow{4}{*}{$\begin{array}{l}\text { One leg stand to } \\
\text { open eye } \\
\text { (sec) }\end{array}$} & $\mathrm{CON}$ & $22.64 \pm 5.34$ & $21.62 \pm 5.00$ & & -4.51 & \multirow{4}{*}{$\begin{array}{c}\text { Group } \\
\text { Test } \\
\text { Group*Test }\end{array}$} & \multirow{3}{*}{$\begin{array}{l}.590 \\
.579\end{array}$} & \\
\hline & LA & $22.17 \pm 4.51$ & $23.03 \pm 3.92$ & & 3.88 & & & \\
\hline & MA & $26.81 \pm 5.25$ & $28.90 \pm 4.60$ & & 7.80 & & & \\
\hline & HA & $28.77 \pm 6.21$ & $30.56 \pm 4.65$ & & 6.22 & & .912 & \\
\hline \multirow{4}{*}{$\begin{array}{l}\text { Functional reach } \\
\qquad(\mathrm{cm})\end{array}$} & $\mathrm{CON}$ & $28.46 \pm 2.02$ & $29.25 \pm 2.02$ & & 2.78 & \multirow{4}{*}{$\begin{array}{c}\text { Group } \\
\text { Test } \\
\text { Group*Test }\end{array}$} & \multirow{3}{*}{$\begin{array}{r}.408 \\
<.001\end{array}$} & \multirow{4}{*}{$\begin{array}{l}+1+ \\
+\end{array}$} \\
\hline & LA & $32.06 \pm 2.15$ & $32.44 \pm 2.10$ & & 1.19 & & & \\
\hline & MA & $30.77 \pm 1.79$ & $33.45 \pm 1.76$ & & 8.71 & & & \\
\hline & HA & $30.10 \pm 1.15$ & $35.16 \pm 1.67$ & $* *$ & 16.81 & & .028 & \\
\hline \multirow{4}{*}{$\begin{array}{c}\mathrm{VO}_{2} \max \\
\left(\mathrm{ml} \cdot \mathrm{kg}^{-1} \cdot \mathrm{min}^{-1}\right)\end{array}$} & $\mathrm{CON}$ & $35.88 \pm 1.49$ & $35.92 \pm 1.61$ & & 0.11 & Group & .341 & \\
\hline & LA & $35.28 \pm 1.24$ & $36.13 \pm 1.44$ & & 2.41 & & 001 & + \\
\hline & MA & $36.21 \pm 1.06$ & $37.59 \pm 1.02$ & & 3.81 & ICSt & & 11 \\
\hline & $\mathrm{HA}$ & $37.19 \pm 1.22$ & $39.99 \pm 1.06$ & $*$ & 7.53 & Group*Test & .069 & \\
\hline
\end{tabular}

\# CON: control group, LA: low intensity aerobic exercise group, MA: moderate intensity aerobic exercise group, HA: high intensity aerobic exercise group, $\mathrm{VO}_{2}$ max: maximal oxygen uptake

$* p<.05 ; * * p<.01 ; * * * p<.001+$ Significant main effect and/or interaction. a, b, c: Different alphabet indicates significant difference. 
기에서는 집단과 검사의 주효과가 유의하게 나타났으며, 악력, 그리고 $\mathrm{VO}_{2} \mathrm{max}$ 에서는 검사의 주효과가 유의하게 나타났다. CON집단은 체력의 모든 변인에서 유의한 변 화는 나타나지 않았다. 반면 LA집단은 앉아 윗몸 앞으로 굽히기 $(p<.01)$ 에서 유의한 변화가 나타났고, MA집단은 악력 $(p<.05)$ 과 6 분 걷기 $(p<.05)$ 에서 유의한 변화가 나타 났으며, HA집단은 악력 $(p<.01)$, 의자에 앉았다 일어서 기 $(p<.01)$, 앉아 윗몸 앞으로 굽히기 $(p<.001), 6$ 분 걷기 ( $p<.01)$, 동적평형성 $(p<.01)$, 그리고 $\mathrm{VO}_{2} \max (p<.05)$ 에 서 유의한 변화가 나타났다(Table. 4).

삶의 질의 변화에서는 $\mathrm{EQ}-\mathrm{VAS}$ 에서 집단과 검의 상호 작용이 유의하게 나타났으며, $\mathrm{EQ}-5 \mathrm{D}$ 에서는 검사의 주효 과가 유의하게 나타났다. $\mathrm{HA}$ 집단과 $\mathrm{CON}$ 집단은 삶의 질 의 유의한 변화가 나타나지 않았다. 반면 LA집단과 $\mathrm{MA}$ 집단은 $\mathrm{EQ}-\operatorname{VAS}(p<.01)$ 의 유의한 변화가 나타났다 (Table. 5).

\section{논 의}

\section{신체구성의 변화}

본 연구에서는 기존에 연구들에서 진행한 단일 강도의 운동강도를 통해 대상자의 생리학적 변화를 연구한 것과 달리 세가지로 분류하여 운동강도별 효과를 규명하고자
하였다. 본 연구의 결과 $\mathrm{MA}$ 집단은 체중 $(p<.05)$ 과 $\operatorname{BMI}(p<.05)$ 에서 유의한 변화가 나타났고, HA집단은 체 중 $(p<.001), \mathrm{BMI}(p<.001)$, 그리고 허리둘레 $(p<.01)$ 에 서 유의한 변화가 나타났다. 반면, CON집단과 LA집단 은 유의한 변화가 나타나지 않았다.

유산소 운동의 운동강도가 $55 \%$ 이하인 경우 신체구성 에 미치는 영향이 적은 것으로 보고하였으며 (Swain \& Franklin, 2006), 본 연구의 결과에서도 확인한 바와 일 치하였다. 반면 MA집단과 $\mathrm{HA}$ 집단에서 체중과 $\mathrm{BM}$ 에서 유의한 변화가 나타났으며, Villareal et al.(2017)도 노 인을 대상으로 HRpeak 65-85\% 강도의 유산소 운동을 실시한 결과, 체중의 유의한 변화를 보고하였다.

유산소 운동 트레이닝을 실시하여 신체구성의 효과를 나타내기 위해서는 저강도 유산소 운동보다는 중-고강도 의 유산소 운동이 효과가 있는 것으로 확인하였으며, Fleg (2012)도 중·고강도의 유산소 운동은 대사기능의 향상과 근력, 근지구력, 평형성 등의 향상으로 신체구성 및 체력 향상에 효과적인 것으로 보고하였다. 노인의 경 우에도 체중 및 체지방량 감량을 목적으로 하는 경우 안 전성과 효과성을 고려한다면 중강도의 운동이 효과적일 것으로 판단된다.

운동강도는 대상자의 건강상태 및 목적에 따라 수행되 며, 그 효과를 얻기 위해 목적에 맞는 운동강도를 수행하 게 된다. 노인을 위한 운동프로그램은 그 효과에 대해서 규명되었으나, 운동효과를 나타내기 위해서는 안정성도

Table 5. Change in quality of life

$(\operatorname{mean} \pm \mathrm{SE})$

\begin{tabular}{|c|c|c|c|c|c|c|c|c|}
\hline Variables & Groups & Pre & Post & & $\Delta \%$ & & \multirow[b]{2}{*}{.841} & \multirow{5}{*}{+} \\
\hline \multirow{4}{*}{$\begin{array}{l}\text { EQ-5D } \\
\text { (score) }\end{array}$} & $\mathrm{CON}$ & $0.91 \pm .02$ & $0.92 \pm .01$ & & 1.10 & \multirow[t]{3}{*}{ Group } & & \\
\hline & LA & $0.91 \pm .02$ & $0.92 \pm .02$ & & 1.10 & & & \\
\hline & MA & $0.92 \pm .01$ & $0.93 \pm .02$ & & 1.09 & & .047 & \\
\hline & HA & $0.88 \pm .02$ & $0.92 \pm .01$ & & 4.55 & Group*Test & .470 & \\
\hline \multirow{4}{*}{$\begin{array}{l}\text { EQ-VAS } \\
\text { (score) }\end{array}$} & $\mathrm{CON}$ & $75.75 \pm 4.43$ & $74.17 \pm 4.03 \mathrm{a}$ & & -2.09 & Group & .038 & + \\
\hline & LA & $78.33 \pm 3.81$ & $90.83 \pm 1.93 b$ & $* *$ & 15.96 & \multirow{2}{*}{ Test } & \multirow{2}{*}{.001} & \multirow{2}{*}{++} \\
\hline & MA & $78.75 \pm 2.14$ & $90.67 \pm 2.55 b$ & $* *$ & 15.14 & & & \\
\hline & $\mathrm{HA}$ & $75.83 \pm 4.34$ & $78.33 \pm 2.97 \mathrm{a}$ & & 3.30 & Group*Test & .018 & + \\
\hline
\end{tabular}

\# CON: control group, LA: low intensity aerobic exercise group, MA: moderate intensity aerobic exercise group, HA: high intensity aerobic exercise group, EQ-5D: euroQol-5 dimension, EQ-VAS: euroQol-visual analogue scale

** $p<.01+$ Significant main effect and/or interaction. a, b: Different alphabet indicates significant difference. 
확보되어야 한다. 특히 노인들이 저체력자임을 감안할 때 운동강도의 변화가 심하거나 고강도일 경우 급성 심혈관 계 이상반응을 유발(Lee \& Jung, 2011; ACSM, 2013) 할 수 있기 때문에 안전을 고려한 운동강도로 실시하는 것이 요구되지만 성인 또는 중년부터 꾸준하게 체력을 관 리한 노인의 경우 연령과 관계없이 고강도 운동을 수행할 수 있으며, 그 효과 또한 큰 것으로 보고되었다(Park \& Han, 2017). 따라서 단순히 연령을 기준으로 하여 권고 되는 운동강도로 제한하여 운동에 대한 효과를 경감시키 는 것 보다는 노인이라 하더라도 개인의 체력과 목적에 맞는 운동을 실시하는 것이 필요하다고 사료된다.

그러나 노인의 경우 성인과 달리 우발적으로 발생될 수 있는 부상과 골절이 우려되며, 회복에도 문제가 심각 하게 발생될 수 있다. 따라서 단순히 목적과 효과가 아닌 건강개선을 위한 목적으로 운동을 접근하는 것이 필요하 며, 운동에 대한 전반적인 인식의 제고와 사회적 차원의 교육이 병행되어야 한다.

\section{건강관련체력의 변화}

본 연구에서는 LA집단은 앉아 윗몸 앞으로 굽히기에 서 ( $p<.01)$ 유의한 변화가 나타났고, MA집단은 6 분 걷 기 ( $p<.05)$ 에서 유의한 변화가 나타났으며, $\mathrm{HA}$ 집단은 악 력 $(p<.01)$, 앉아 윗몸 앞으로 굽히기 ( $p<.001), 6$ 분 걷기 ( $p<.01)$, 동적평형성 $(p<.01)$ 에서 유의한 변화가 나타났 다. 반면, $\mathrm{CON}$ 집단은 유의한 변화가 나타나지 않았다.

유산소 운동이 노인의 체력을 유지 및 개선시키는데 효과적이라는 것은 여러 연구에서 검증되었으나, 본 연구 에서는 통제집단을 포함하여 4 개의 집단의 효과를 규명 하고자 하여 통계적인 차이를 나타내기에는 다소 부족하 였다. 그러나 사전-사후 변화량을 확인한 결과 중, 고강 도의 유산소 운동이 노인의 체력의 변화에 긍정적인 영향 을 줄 수 있을 것으로 사료된다. 이와 관련하여 Lee et al. (2010)은 노인을 대상으로 적용한 장기간 시니어 에 어로빅이 근력을 향상시키는데 효과적인 것으로 보고하 였으며, 폐경기 여성을 대상으로 24주간 70 80\% HRR 의 강도로 유산소 운동을 실시한 Karacan(2010)의 연구 에서도 근지구력이 유의하게 향상된 것으로 나타나, 본 연구의 결과를 뒷받침하고 있다. 또한 당뇨병 노인여성을
대상으로 8주간 유산소 운동을 실시한 Choi et al. (2016)의 연구에서는 8주간 HRR 50 70\%의 유산소 운동을 실시한 결과, 동적평형성의 통계적인 차이가 나타 나지 않았으나, 트레이닝 집단의 의미있는 변화를 제시하 였다. 선행연구와 달리 본 연구에서는 12 주간 $\mathrm{HRR} 70 \%$ 이상의 유산소 운동을 실시하였고, 이러한 결과는 고강도 유산소 운동 시 빠르게 걷거나 달리기 위해서는 상체와 하체를 빠르게 교차시켜야 한다. 이와 관련하여 Cress et al. (2006)은 유산소 운동 시 하지, 복부, 상체의 전신 근 육의 사용과 더불어 관절의 가동범위를 증대시켜 평형성 과 관련된 균형능력 향상에 효과적이라고 보고하여 본 연 구이 결과를 뒷받침하고 있다.

노인의 규칙적인 운동 프로그램의 참여는 신체구성, 심폐기능, 근력 및 근지구력, 관절의 유연성, 평형기능 등 의 건강관련체력에 영향을 미치는 것으로 보고되었다 (McPhee et al., 2016). 본 연구의 결과, 유산소 운동에 참여한 집단에서는 강도별 건강관련체력 변인 간 차이는 다르게 나타났으나, 건강관련체력의 긍정적인 변화가 나타 났으며, 특히 HA집단에서 그 효과가 큰 것으로 나타났다.

\section{삶의 질의 변화}

본 연구에서는 유산소 운동강도 따른 삶의 질의 개선 정도를 규명하고자 $\mathrm{EQ}-5 \mathrm{D}$ 와 $\mathrm{EQ}-\mathrm{VAS}$ 를 측정한 결과, 모든 집단은 $\mathrm{EQ}-5 \mathrm{D}$ 에서 유의한 차이는 나타나지 않았으 나, $\mathrm{LA}$ 집단과 $\mathrm{MA}$ 집단은 $\mathrm{EQ}-\mathrm{VAS}(p<.01)$ 에서 유의한 변화가 나타났다.

$\mathrm{EQ}-\mathrm{VAS}$ 와 $\mathrm{EQ}-5 \mathrm{D}$ 의 효용성을 비교한 $\mathrm{Kim}$ et al. (2008)은 $\mathrm{EQ}-\mathrm{VAS}$ 와 $\mathrm{EQ}-5 \mathrm{D}$ 의 경우 일반인의 삶의 질을 평가하기보다는 우울 및 불안과 같은 심리적인 문제 를 가지고 있는 사람에게 그 효용성이 높다고 보고하였 다. 본 연구에서 $\mathrm{EQ}-5 \mathrm{D}$ 의 유의한 변화가 나타나지 않은 것은 심리적인 문제가 없는 일반인을 대상으로 실시하였 으며, 사전에 $\mathrm{EQ}-5 \mathrm{D}$ 를 측정한 값이 높은 것으로 볼 때, 그 변화가 미비한 것으로 판단된다.

$\mathrm{EQ}-\mathrm{VAS}$ 에서는 LA집단과 MA집단에서 유의한 변화 가 나타난 것은 신체활동을 통한 체력의 향상과 상관성이 있는 것으로 판단되며, Lee \& Kim(2008)은 노인 여성 을 대상으로 12 주간 중강도의 짐볼 운동을 실시한 결과, 
체력(근력, 유연성, 평형성)과 삶의 질의 향상을 보고하 였고, Park et al.(2014)의 연구에서 체력과 삶의 질의 상관성이 높은 것으로 보고하여 본 연구의 결과를 지지하 고 있다. 또한 그러나 HA집단의 경우 $\mathrm{EQ}-\mathrm{VAS}$ 의 유의한 변화가 나타나지 않았는데 이는 고강도 유산소 운동이 노 인에게 행복감을 주기에는 다소 힘든 환경을 제공한 것으 로 판단되며, Marjan et al.(2006)은 노인의 경우 상해 에 대한 불안감으로 인하여 고강도 운동은 심리적인 부담 을 줄 수 있다는 것으로 보고하여 본 연구의 결과를 뒷받 침하고 있다. 따라서 노인의 경우 삶의 질의 향상을 위해 서는 심리적인 안정감을 줄 수 있으며, 상해에 대한 두려 움이 낮은 저·중강도의 운동에 참여하는 것이 장기간 지 속적인 참여에 대한 동기부여가 될 것이라고 사료된다. 따라서 노인의 경우 운동의 효과만을 목적으로 하기보다 는 심리적 안정과 더불어 지속적 참여가 가능한 운동 프 로그램을 적용하는 것이 효과적일 것이다.

\section{결 론}

본 연구의 목적은 노인 여성을 대상으로 12 주간 유산 소 운동강도별 처치를 실시하여 노인 여성의 신체구성, 체력, 그리고 삶의 질에 미치는 영향을 규명하는 것이었 으며, 본 연구의 주요 결과는 다음과 같다.

1) LA집단에서는 앉아 윗몸 앞으로 굽히기의 유의한 감소와 $\mathrm{EQ}-\mathrm{VAS}$ 의 유의한 증가가 나타났다.

2) $\mathrm{MA}$ 집단에서는 체중, $\mathrm{BMI}, 6$ 분 걷기의 유의한 감 소와 악력, $\mathrm{EQ}-\mathrm{VAS}$ 의 유의한 증가가 나타났다.

3) HA집단에서는 체중, BMI, 허리둘레, 앉아 윗몸 앞 으로 굽히기, 6 분 걷기의 유의한 감소와 악력, 의자 에 앉았다 일어서기, 동적평형성, $\mathrm{VO}_{2} \mathrm{max}$ 의 유의 한 증가가 나타났다. 반면, $\mathrm{CON}$ 집단에서는 모든 변인에서 유의한 변화가 나타나지 않았다.

이상의 결과를 토대로 12 주간 실시한 유산소 운동은 노인여성의 신체구성, 체력, 그리고 삶의 질에 효과적이 며, 특히 고강도 유산소 트레이닝이 건강과 관련된 다양 한 효과가 있는 것으로 결론지을 수 있다.
한편, 노인의 경우 고강도 운동이 체력을 증가시키는 데 효과적이지만 운동 중 심리적 불안감이 높은 부분을 고려하여 다소 체력의 향상이 유의하게 나타나지 않을 수 있으나 유연성과 근지구력 같은 건강관련체력의 향상과 심리적 만족도에 영향을 줄 수 있는 저-중강도의 운동에 참여하는 것이 필요하다.

현재 다양한 운동 프로그램이 개발 및 검증되어 보급 되었으나, 개인의 특성에 맞는 운동프로그램을 적용하기 는 쉽지 않은 실정이다. 또한 자신의 목적과 달리 무조건 낮은 강도의 운동에 참여하는 것은 본래 목적과 달리 효 과가 나타나지 않을 수 있다.

추후 노인을 대상으로 다양한 운동 프로그램을 강도별 로 실시하여 건강관련체력과 심리적인 부분에 긍정적인 효과를 미칠 수 있는 노인 맞춤형 운동 프로그램을 연구 하는 것이 필요할 것으로 사료된다.

\section{참고문헌}

American College of Sports Medicine. (2010). ACSM'S Guidelines for Exercise Testing and Prescription. 8th Edition. Lippincott, Williams \& Wilkins: Philadelphia, PA.

American College of Sports Medicine. (2013). ACSM'S Guidelines for Exercise Testing and Prescription. 8th Edition. Lippincott, Williams \& Wilkins: Philadelphia, PA.

Bauman, A., Merom, D., Bull, F. C., Buchner, D. M., Fiatarone Singh, M. A. (2016). Updating the evidence for physical activity: summative reviews of the epidemiological evidence, prevalence, and interventions to promote "active aging". The Gerontologist, 56(Suppl_2), S268-S280.

Bechshøft, R. L., Reitelseder, S., Højfeldt, G., Castro-Mejía, J. L., Khakimov, B., Ahmad, H. F., Kjær, M., Engelsen, S. B., Johansen, S. M., Rasmussen, M. A., Lassen, A. J., Jensen, T., Beyer, N., Serena, A., Perez-Cueto, F. J., Nielsen, D. S., Jespersen, A. P., Holm, L. (2016). Counteracting Age-related Loss of Skeletal Muscle Mass: a clinical and ethnological trialon the role of protein supplementation and training load (CALM Intervention Study): study protocol for a randomized controlled trial, Trials, 17(1), 397. 10.1186/s13063-016$1512-0$

Bize, R., Johnson, J.A., Plotnikoff, R. C. (2007). Physical activity 
level and health-related quality of life in the general adult population: A systematic review. Preventive Medicine, 45(6), 401-415.

Choi, H. A., Kim, Y. Y., Lee, M. G. (2016). Effects of 8 weeks of aerobic training and resveratrol on physical fitness, insulin resistance, liver function, and blood pressure in T2DM elderly women. Korean Journal of Sport Science, 27(3). 507-522.

Chou, C. H., Hwang, C. L., Wu, Y. T. (2012). Effect of exercise on physical function, daily living activities, and quality of life in the frail older adults: a meta-analysis. Archives of Physical Medicine and Rehabilitation, 93(2), 237-244.

Chung, J. W. \& Sung, S. C. (2013). The effect of applying u-health system on metabolic syndrome management of elderly. The Society of Digital Policy and Management, 11(11), 553-560.

Cress, M. E., Buchner, D. M., Prohaska, T., Rimmer, J., Brown, M., Macera, C., Dipietro, L., Chodzko-Zajko, W. (2006). Best practices for physical activity programs and behavior counseling in older adult populations. Journal of Aging and Physical Activity, 13(1), 61-74.

Delforge, M., Dhawan, R., Robinson, D., Meunier, J., Regnault, A., Esseltine, D. L., San Miguel, J. F. (2012). Health related quality of life in elderly, newly diagnosed multiple myeloma patients treated with VMP vs. MP: results from the VISTA trial. European Journal of Haematology, 89(1), 16-27.

EuroQol Group. (1990). EuroQol-a new facility for the measurement of health-related quality of life. Health Policy, 16(3), 199-208.

Faul, F., Erdfelder, E., Buchner, A., Lang, A. G. (2009). Statistical power analyses using $\mathrm{G}^{*}$ Power 3.1: tests for correlation and regression analyses. Behavior Research Methods. 41(4), 1149-1160.

Fleg, J. L. (2012). Aerobic exercise in the elderly: a key to successful aging. Discovery Medicine, 13(70), 223-228.

Gibala, M. J., Little, J. P., MacDonald, M. J., Hawley, J. A. (2012). Physiological adaptations to low-volume, high-intensity interval training in health and disease. The Journal of Physiology, 590(5), 1077-1084.

Hall, P. A. \& Marteau, T. M. (2014). Executive function in the context of chronic disease prevention: theory, research and practice. Preventive Medicine, 68, 44-50.

Jak, A. J. (2011). The impact of physical and mental activity on cognitive aging. Current Topics in Behavioral Neurosciences, 10, 273-291.
Kang, C. K., Kim, H. J., Lee, M, G. (2014). Effects of 12 weeks of vitamin D supplementation and circuit training of falling injury-related variables in T2D and vitamin D deficient elderly women. Korean Journal of Sports Science, 23(5), 1399-1409.

Karacan, S. (2010). Effects of long term aerobic exercise on physical fitness and postmenopausal symptoms with menopausal rating scale. Science and Sports, 25, 39-46.

Kim, H. J., Rhee, J. N., Lee, E. K. (2008). VAS(Visual Analogue Scale), TTO(Time Trade-Off), EQ-5D(EuroQol-5) Measuring Utility Weights with VAS, TTP and EQ-5D for Severe Stomach Cancer. Archives of Pharmacal Research, 52, 176-181.

Kim, J. Y., Park, H. J., Lee, I. S. (2012). The effects of group art therapy with Hanji, Korean paper, to improve the quality of life of elderly stroke patients. Journal of the Korea Gerontological Society, 32(1), 87-102.

Kim, K. L., Kim, J. H., Park, J. K. (2005). The Extent of the Middle-aged's Living Participation and the Effects of Considering Their Old Age on the Preferred Type of Gymnasiums and Environment for the Old. Korean Society of Sports and Leisure Studies, 24, 425-436.

Kim, N. J. (2007). Relation between Employees' Life patterns and Health conditions. Korean Journal of Health Education and Promotion, 24(2), 63-75.

Kim, O. J. \& Ahn, C. W. (2014). Effects of Perceived Belief in Sports Activity on Self-Esteem and Quality of Life in People with Physical Disabilities. Korean Journal of Sports Science, 23(5), 467-479.

Korea Institute for Health and Social Affairs. (2017). 2017 Older People Survey in Korea.

Landaeta-Diaz, L., Fernández, J. M., Da Silva-Grigoletto, M., Rosado-Alvarez, D., Gómez-Garduño, A., Gómez-Delgado, F., Fuentes-Jiménez, F. (2013). Mediterranean diet, moderate-to-high intensity training, and health-related quality of life in adults with metabolic syndrome. European Journal of Preventive Cardiology, 20(4), 555-564.

Laudisio, A., Marzetti, E., Antonica, L., Pagano, F., Vetrano, D. L., Bernabei, R., Zuccalà, G. (2013). Metabolic syndrome and quality of life in the elderly: age and gender differences. European Journal of Nutrition, 52(1), 307-316.

Lee, C. G., Boyko, E. J., Nielson, C. M., Stefanick, M. L., Bauer, D. C., Hoffman, A. R., Orwoll, E. S. (2011). Mortality risk in older men associated with changes in weight, lean mass, and 
fat mass. Journal of the American Geriatrics Society, 59(2), 233-240.

Lee, H. S., \& Kim, H. (2008). The influence of the gym-ball exercise program on the health fitness strength and life quality of the old female. The Korea Journal of Sports Science, 17(2), 915-927.

Lee, J. C., Bae, J. J., Her, A. S., Park, G. D. (2011). The Effects of Exercise on Physical Function and Quality of Life in Elderly Chronic Disease Patience. The Korean Journal of Growth and Development, 19(4), 313-318.

Lee, J. W. \& Jung C. W. (2011). The Effects of Regular Aquarobics on Instrumental Activities of Daily Living, Body Composition, and Sleep Quality in Elderly Women. Korean Gerontological Nursing Society, 13(1), 11-20.

Lee, S. C., Nishita, Y., Tange, C., Otsuka, L., Fujiko, A., Shimokata, H., Chang, M. J., Choi, H. M. (2011). Association between Comprehensive Physical Functions and Cognitive Impairment in a Community-dwelling Elderly Population : 8-year Longitudinal Study. The Korean Society of Living Environmental System, 22(5), 679-687.

Marengoni, A., Angleman, S., Melis, R., Mangialasche, F., Karp, A., Garmen, A., Fratiglioni, L. (2011). Aging with multimorbidity: a systematic review of the literature. Ageing Research Reviews, 10(4), 430-439.

Marjan, J. F., Ruud J. B., Marijke, J. C., Piet, C. W. (2006). Effects of exercise programs on falls and mobility in frail and pre-Frail older adults: A multicenter randomized controlled trial. Archives of Physical Medicine and Rehabilitation, 87(7), 885-896.

McPhee, J. S., French, D. P., Jackson, D., Nazroo, J., Pendleton, N., Degens, H. (2016). Physical activity in older age: perspectives for healthy ageing and frailty. Biogerontology, 17(3), 567-580.

Ministry of Culture, Sports and Tourism. (2012). 2012 National Sport Participation Survey in Korea.

Ministry of Health and Welfare. (2006). 2005 Korean National Health and Nutritional Examination Survey.

Newman, A. B., Lee, J. S., Visser, M., Goodpaster, B. H., Kritchevsky, S. B., Tylavsky, F. A., Nevitt, M., Harris, T. B. (2005). Weight change and the conservation of lean mass in old age: the Health, Aging and Body Composition Study. American Society for Clinical Nutrition, 82(4), 872-878.

Ock, M., Jo, M. W., Lee, S. I. (2013). Measuring health related quality of life using EQ-5D in South Korea. Journal of the
Health Technology Assessment, 1(1), 103-111.

Oh, H. O. (2014). Relationship between Social Capital, Depression and Quality of Life in Elderly People Participating in Physical Activity. Korean Journal of Physical Education, 53(3), 535-547.

Park, D. S. \& Yang, S. H. (2017). The Effects on Body Composition and Health Fitness of 12-Week three types Exercises for Obesity Elderly Women . The Korea Journal of Sports, 15(1), 405-415.

Park, J. \& Han, D. (2017). Effects of high intensity aerobic exercise on treadmill on maximum-expiratory lung capacity of elderly women. Journal of Physical Therapy Science, 29(8), 1454-1457.

Park, J. A. \& Kim, S. Y. (2014). Effects of Tai Chi Exercise on Physical Fitness and Quality of Life in Elderly Women. Korean Academic Society of Rehabilitation Nursing, 17(1), 38-47.

Park, S. J., Song. H. S., Kim, K. J., Jin, Y. Y., Kim, H J. (2014). Effects of Korean National Fitness Award Program Group Exercise on Daily Fitness and Balance Confidence among the Elderly Participants. Korean Journal of Sport Science, 25(4), 650-663.

Park, S. M. \& Yang, J. O. (2012). The Effects of 12 weeks of Combined Exercise Program on the Body Composition and Metabolic Syndrome Risk Factors in the Obese Elderly Women. Korean Journal of Exercise Rehabilitation, 8(1), 121-133.

Phillips, E. M., Schneider, J. C., Mercer, G. R. (2004). Motivating elders to initiate and maintain exercise. Archives of Physical Medicine and Rehabilitation, 85, 52-57.

Pietrzak, R. H., Tsai, J., Kirwin, P. D., Southwick, S. M. (2014). Successful aging among older veterans in the United States. The American Journal of Geriatric Psychiatry, 22(6), 551-563.

Ranzijn, R. (2010). Active ageing--another way to oppress marginalized and disadvantaged elders?: Aboriginal Elders as a case study. Journal of Health Psychology, 15(5), 716-723.

Rikli, R. E., \& Jones, C. J. (2013). Senior fitness test manual. Human Kinetics.

Santos, D. A., Silva, A. M., Baptista, F., Santos, R., Vale, S., Mota, J., Sardinha, L. B. (2012). Sedentary behavior and physical activity are independently related to functional fitness in older adults. Experimental Gerontology, 47(12), 908-912.

So, W. Y., Hong, J. Y., Jun, E. J., Choi, D. H., Kim, K. H. (2010). 
Effects of Aquarobics Exercise on Body Composition, Fitness and Health Related Quality of Life(SF-36) in Elderly Women. The Korean Gerontological Society, 30(3), 683-694.

Statistic Korea. (2018). 2018 Statistic on the aged.

SunWoo, D., Lee, S. H., Park, J. S., Bae, S. S., Cho, Y. H., Kim, C. B., Koh, K. W., Kim, Y. A. (2008). Analysis of the Effects of Muscle Strength Exercise on Physical Function and Quality of Life in the Frail Elderly. Korean Society for Health Education and Promotion, 25(1), 39-53.

Swain, D. P. \& Franklin, B. A. (2006). Comparison of cardioprotective benefits of vigorous versus moderate intensity aerobic exercise. The American Journal of Cardiology, 97(1), 141-147.

Swift, D. L., Lavie, C. J., Johannsen, N. M., Arena, R., Earnest, C. P., O'Keefe, J. H., Church, T. S. (2013). Physical activity, cardiorespiratory fitness, and exercise training in primary and secondary coronary prevention. Circulation Journal, 77(2), 281-292.

Villareal, D. T., Aguirre, L., Gurney, A. B., Waters, D. L., Sinacore, D. R., Colombo, E., Armamento-Villareal, R., Qualls, C. (2017). Aerobic or resistance exercise, or both, in dieting obese older adults. New England Journal of Medicine, 376(20), 1943-1955.

WHO. (2010). Global Recommendations on Physical Activity for Health. Geneva, Switzerland.

Wojtek, J., David, N., Maria, A., Christopher, T., Claudio, R., George, J., James, S. (2009). Exercise and Physical Activity for Older Adults. Medicine and Science in Sports and Exercise, 41(7), 1510-1530.

Woods, J. A., Wilund, K. R., Martin, S. A., Kistler, B. M. (2014). Exercise, inflammation and aging. Aging and Disease, 3(1), 130-140.

Yim, E. S. \& No, K. H. (2010). The Effects of Related Factors on Health-related Quality of Life for the Frail Elderly. Journal of Korean Academy of Community Health Nursing, 21(1), 12-20.

Yoon, H. G., \& Kim, D. H. (2011). The Effect of Physical and Social Abilities of Elders Participating in Billiard Activity on Leisure Satisfaction and Quality of Life. Korean Journal of Sports Science, 20(5), 171-182.

Zhao, .L., Wu, H., Zhou, X., Wang, Q., Zhu, W., Chen, J. (2012). Effects of progressive muscular relaxation training on anxiety, depression and quality of life of endometriosis patients under gonadotrophin-releasing hormone agonist therapy. European
Journal of Obstetrics, Gynecology, and Reproductive Biology, 162(2), 211-215. 


\title{
노인 여성의 유산소 운동강도별 트레이닝이 신체구성, 건강관련체력 및 삶의 질에 미치는 영향
}

\author{
김형준 ${ }^{1}$, 박준성 ${ }^{2}$ \\ 1리안소프트, 연구소장 \\ ${ }^{2}$ 신라대학교, 조교수
}

[목적〕 본 연구의 목적은 노인 여성을 대상으로 유산소 운동강도별 트레이닝이 신체구성, 건강관련체력, 그리고 삶의 질에 미치는 영향을 규명하는 것이다. 〔방법〕 신체적·정신적인 문제가 없는 65 세 이상의 노인 여성 48명을 통제집단 (control: CON 집단), 저강도 유산소 운동집단 (low intensity aerobic exercise group: LA 집단), 중강도 유산소 운동집단 (moderate intensity aerobic exercise group: MA 집단), 고강도 유산소 운동집단 (high intensity aerobic exercise: HA 집단) 네 집단으로 12 명씩 무선할당 하였 다. 유산소 운동 집단의 대상자는 여유심박수(heart rate reserve: HRR)를 적용하여 12 주간, 주 3회, 1 일 20분간 LA집단 (HRR 40-55\%), MA집단 (HRR 55-70\%), HA집단 (HRR >70\%로 실시하였으며, 통제 집단의 대상자는 동일한 중재 기간 동안 평소의 생활습관을 그대로 유지하도록 하였다. 신체구성, 건강관련체 력, 그리고 삶의 질을 측정한 후 반복 이원변량분석을 이용하여 분석하였다. 〔결과〕 본 연구에서 얻은 주요 결과는 다음과 같다. 1) LA집단에서는 앉아 윗몸 앞으로 굽히기의 유의한 감소와 EQ-VAS의 유의한 증가가 나타났다. 2) MA집단에서는 체중, BMI, 6 분 걷기의 유의한 감소와 악력, EQ-VAS의 유의한 증가가 나타났 다. 3) $\mathrm{HA}$ 집단에서는 체중, BMI, 허리둘레, 앉아 윗몸 앞으로 굽히기, 6 분 걷기의 유의한 감소와 악력, 의자 에 앉았다 일어서기, 동적평형성, $\mathrm{VO}_{2} \max$ 의 유의한 증가가 나타났다. 반면, $\mathrm{CON}$ 집단에서는 모든 변인에서 유의한 변화가 나타나지 않았다. 〔결론〕 본 연구에서 얻은 결과를 종합하면, 유산소 트레이닝은 노인여성의 신체구성, 건강관련체력, 그리고 삶의 질에 효과적인 것으로 나타났다. 특히 고강도 유산소 트레이닝은 건강관 련체력에 효과적이며, 저·중강도 유산소 트레이닝은 삶의 질 향상에 효과가 있는 것으로 결론지을 수 있다.

주요어: 노인 여성, 유산소 운동, 신체구성, 건강관련체력, 삶의 질 